\title{
The Development of the Project-based-learning Teaching Method
}

\author{
Yidi Xiong ${ }^{1,2, *}$ \\ ${ }^{1}$ School of Civil Engineering, ChongQing University, ChongQing, ChongQing400000, China \\ ${ }^{2}$ School of Civil Engineering, Hong kong Polytechnic University, Hong Kong 117417, China \\ *Corresponding author. Email: Yidixiong@usaedu.net
}

\begin{abstract}
Project-based learning (PBL) is not only a practical technology but also a new teaching model. By choosing the curriculum content related to real life, students can experience the process of small combination, group selfexploration, result from summary and evaluation, master the required knowledge and skills, and improve their comprehensive thinking ability and social communication ability. It can help students master mathematical knowledge and methods to solve practical and challenging problems and improve their core mathematical ability to adapt to future development. Moreover, this kind of teaching method develops rapidly both at home and abroad.
\end{abstract}

Keywords: project-based -learning, science study, students' cooperation, new type of learning method, practical problem solving

\section{INTRODUCTION}

The development of social economy and culture inspires a fierce desire for creation and innovation in many areas. Especially in the field of education, traditional educational methods cannot be adapted to every curriculum. Currently teachers are more likely to dominate the learning process even though the learning provided is oriented towards problem solving, so students are less actively involved in the learning process. This can be seen from the lack of multidirectional interaction between the teacher and students, as well as between fellow students. Students are more likely to wait or receive information from the teacher and the lack of student initiative to actively seek information related to problem solving both individually and in groups[10].The concentration of students is easily dispersed because the methods used are not appropriate, there are still many students who have not been challenged in answering problem solving, many students are sleepy during class hours, do other activities such as telling stories with their peers or fussing when the teacher presents learning material[10]. Furthermore, some professional curriculum may require the more practical ability for students. Project-based learning(PBL) or problem-based learning teaching method is a set of teaching methods to design learning situations. It refers to the teaching method of problem learning or project learning. The Project-Based Learning methodology (PBL) emerged from the innovative trends of the early 20th century in 1918. William Heart Kilpatrick laid the foundations of this methodology, guided by the "experimental philosophy of education" that guides student learning based on their life experiences[9]. Moreover, it originated from medical education in the 1950s and was initiated by barrow, an American professor of Neurology at McMaster University in Canada, in 1969. Now it is adopted by many medical schools in the world.Unlike the traditional teaching model, the PBL teaching method is a problem-oriented teaching method based on the realworld student-centred teaching method. From a large amount of practical experience, this new teaching mode greatly stimulates students' interest in learning, cultivates students' independent learning ability, and enhances students' comprehensive thinking and innovation ability.However, we need to fully understand the development and characteristics of this new model to implement it scientifically.

\subsection{Related Work}

According to the generation development and characteristics of different areas and times, we divided the 
existing work into two aspects: domestic and overseas.Then we will keep our eyes to the theory development and practice development.

\subsubsection{PBL theory development of overseas}

As mentioned in the introduction, the PBL method was first applied to the practice of medical curriculum in the 1950s. And then take this opportunity to spread to many fields and many countries. Then, in the highly acclaimed series of "very brief introductions" by Oxford University Press, a new book on education was published a few years ago (Thomas 2013). John Dewey's name appears in the preface's first paragraph, juxtaposed with Einstein, Newton, Darwin, and Marx. Dewey is known as "the greatest educational thinker in modern times" and as an "American cultural philosopher", which defines "American spirit" [11]. Psychology and pedagogy. According to this book, John Dewey proposes that impulse is the instinct and desire to work freely in the human world. They are like the laws of nature. It also refers to progress, blindness and spontaneity as freedom, and atom as individuality. He tried to explain the relationship between habit and learning and further showed that learning is practical and learning to the maximum extent from practicality. First of all, habit and impulse are Dewey's terms used to express unconsciousness and instinct. They are practical to life and living.then, "knowing how" is the practical function of knowledge and "knowing that" (of, about things) is the reflection and conscious appreciation of the undescribed thing (reality). When habits and impulses fail, Dewey calls in intelligence.[11]Therefore, from a psychological perspective to understand the nature of learning, how to more practically applied to education. Briefly stated, Psychology deals with the adult with a "mind," a "self", and "consciousness." Education will mean applying these ideas to children, often mistakenly seen as young adults. In conclusion, education is living and active. Learning is not passive listening but is active engagement and thinking when the will is to coordinate and regulate impulse[11]. The PBL teaching model emphasizes the need for teachers to immerse students in practical situations and learn. Students who have more practical goals for their learning will also have more substantial guidance than passive as traditional teaching to absorb knowledge.Our traditional teaching methods, mainly teachers, referred to as irrigation-type teaching, prompt people to build a selfish, mean mind-passive learning and selfish absorption that only choose helpful to their learning. Lacking essential independent thinking and did not want to take their ideas to share with other people. What is more, traditional science teaching is more tedious, making children lose interest in the study. However, according to the National Education System Act No. 20 of 2003, education is a conscious and planned endeavor to create an atmosphere of learning and learning so that students can actively develop their potential and make them religious, Spiritual power, selfcontrol, individuality, intelligence, and noble character, it needs the skills of oneself, society, nation, and country[10]. The emergence of the PBL mode can improve the traditional teaching problems.Project-based learning promotes students' active learning by strengthening the learning of educational skills in an interdisciplinary and multidisciplinary way, but it also integrates the values of cooperation, organization, and time management in a practical way [9].

\subsubsection{PBL practice development of overseas}

Since the medical application of PBL to obtain good results, this teaching model in all disciplines of learning has been fully applied. Such as the subject "mathematics in engineering" refers to mathematics as a service subject for engineering programs, usually taught by mathematicians, and mathematics as an integrated part of engineering sciences, where it constitutes specific practices with mathematics being more than just a language for engineers.[8] It is easier to achieve better learning results with PBL mode for this kind of integrated subject learning. This system of project implementation is quite common in higher education. For its implementation in secondary and primary education in Spain, the current educational law (LOMCE - the organic law for improving the quality of education. Organic Law 8/2013, 9 December) includes Project-Based Learning to enhance learning students are able to achieve competence in all subjects. It is considered adequate to motivate students from early ages towards STEM disciplines and also serves as training for the work dynamics that students will follow in their academic and professional future. In the metaanalysis from 1998 to 2017, it is evident that projectbased learning significantly improves compared with traditional methods [9]. With the progress of model science and technology, we can explore more possibilities of the network in the project-based learning environment. Students conduct team projects in this environment and present them on the Internet. In particular, the works constantly displayed on the Internet during the semester stimulate more fierce competition among students and expect to achieve higher goals [12]. Some projects are outstanding and worthy of better recording on the web, which can also serve as examples and inspiration for current and future students [12].

\subsubsection{PBL theory development of domestic situation}

Project-based-learning(PBL) was first introduced to our country in the 1990s, which precisely in 1995 Science Class magazine published the German Ms Annelize Pollack in the Sino-German natural common 
sense seminar and initially introduced the "German hometown common sense course project design teaching examples" two translations. This paper introduces the value of the project teaching method and its application in primary education in Germany and expounds on the role of project teaching method in enterprise training in the 12th issue of "China Training" in 1999, entitled "project learning method - a useful attempt". Even in China, project-based learning (PBL) is still a new thing. It has only been launched nearly 20 years and is still in the stage of development. Most of the applications from universities, secondary schools and vocational schools seldom go to primary schools. Each school develops by itself, and there is a lack of cooperation and information exchange between schools. The results in uneven progress at the level of project learning in each school. However, we all know that research is an important method of learning, and design is an important way to learn technology and engineering. Scientific Practice Can help students understand the development process of scientific knowledge, thus to better understand scientific concepts. Students can better understand the role of scientific engineering on social problems through hands-on operation. Furthermore, there are a lot of experiments and experiments based on the PBL teaching mode in China. It is recommended that Project-based-learning is worthy of promotion, promoting students to learn a new way of learning effectively. Foreign project learning has been widely used and has formed a complete theoretical system.

\subsubsection{PBL practice development of domestic}

Projected learning is a teaching method that gives students complete activities, which is in line with the modern teaching concept. This new teaching method has been applied in many school courses, especially in primary schools; in the "food tour" project, teachers can first edit and present documentaries about food through information technology. Teachers can display the content of "China on the Tip of the Tongue", which will display a variety of colors and flavors of food in front of students. At the same time, teachers need to try to choose local food to select materials to make students immersed in the atmosphere of the project[1]. At the end of the short film, the teacher can ask the students: "Students, we eat much food every day, then you know where the food go?" Then introduce specific exploration content. The daily topic of food in life can effectively stimulate students' interest in learning and live classroom atmosphere up, which definitely lay a solid foundation for the future activities of the future[5]. Teachers can introduce project learning into teaching primary school English, with students as the main body, training students' high-level thinking ability, selfmanagement and evaluation ability, and improving students' core literacy.In primary school English classrooms, teachers should rely on teaching materials to re-integrate or reconstruct teaching materials, so that teaching materials become the thinking of primary school students 'running horse farm'. When teaching in the unit as a whole, teachers can integrate language learning into the unit with the help of the projects of interest to students, and combine the topics of this module to set up effective situations, so as to promote students to improve their logical thinking ability in the communication of words. As project learning comes from the real situation, and the situation is everchanging, which will cause the endless problem. We should establish a inextricably linked in the input and output process and thinking of English language, to promote students' logical thinking, critical thinking, creative thinking and other thinking ability. Students also in the process of completing the task of continuous observation and analysis and make reasonable judgments. This project-based learning process of "observing pictures, asking questions, checking and guessing" effectively cultivates students' ability of observation, judgment, and logical thinking. Engineering practice is an interdisciplinary projectbased learning method. Scientific practice can help students understand the scientific knowledge of the development process and better understand scientific concepts through research. In addition, engineering practice can help students better connect subject concepts, general concepts, and engineering design. Students can better construct the meaning of science and engineering practice and understand the role of science. Solve social problems through the hands-on operation. In carrying out scientific project-based learning, primary schools should strengthen inter-school cooperation, share resources, provide more adequate conditions for project-based learning, strengthen teacher exchanges, share practical experience, and organize better and guide projects to learn. Mainly, strengthen cooperation and sharing of results, and promote them to complete project-based learning more deeply.Project-learning is also suitable as a foundation for interdisciplinary learning.

\subsection{Our Contribution}

According to the PBL teaching method experiments and practices in domestic or overseas, it can conclude the basic procedures and key tips about the project learning. The first is to combine curriculum research to clarify the project tasks; second, to set up a realistic situation to invigorate the classroom atmosphere; third, to let the students make their plans, the teacher will play the role of the instructor, review the plan, and give guidance, and then help them to carry out the effective division of labor. Fourth, ensure the implementation of the research; finally, evaluate and use it to achieve a practical summary [4]. Furthermore, concerning the role of the teacher, As the guide of student learning, what can be done is to help students clear the direction 
and objectives of learning, choose the proper methods and means, guide students to complete the exploration safely and effectively, rather than mechanically teaching knowledge to students, so that students passively accept and learn. To jump out of the traditional teaching model with teachers as the core, the design of questions in teachers' teaching design is the key, that is, how teachers put forward core questions and driving questions, how to guide students correctly, how to let students have a collision of thinking, in the project activities to let learning really happen, these are the problems that teachers need to seriously consider of course, there still some problems we should notice during the process of project. For example, the setting of the program should close to the situation of students, and only When students realize that their research results can be put into practice, and benefit society and human beings, the students' internal drive to learn will be significantly enhanced[3]. second, the division of groups in the PBL should be clear, such as the team leader taking on the role of the decision-maker, acting as a think tank for planning, and taking on design responsibilities[3]. Third, the PBL model can also really realize student-oriented learning and treat the student as an active, capable of solving problems of the individual. Focus on the child's entire learning process, not the final exam. From the evaluation subject, there are students' self-evaluation, students' mutual evaluation, teachers' evaluation, school evaluation, parents' evaluation, social evaluation and so forth[7]. However, it is challenging to realize the domestic PBL mode as the mainstream environment, and there is still a long way to go.

\section{CONCLUSION}

In today's primary school science teaching, project teaching can also play an important role. In teaching, teachers need to do the following: first, they need to clarify the project tasks in combination with the curriculum research, to activate the classroom atmosphere on the spot; Secondly, find a reasonable way to help students make plans; Ensure the implementation of the plan through practical work; Contact the teaching material test to explore the results, and cooperate with the corresponding assessment test homework to summarize effectively. Teachers do the above content to let students promote each other in learning and reflection, constantly improve their teaching efficiency, and better adapt to the higher requirements of today's society. On the other hand, this methodology requires a high level of dedication and training from the teacher to improve their selfefficiency . In addition, to optimize learning, it is advisable to have projects that have already been elaborated and evaluated, promoting a collaborative dynamic among students[9].However,PBL is a learning model that still focuses on students or student centers. And PBL model is closely related to problems that occur in real life and is learning that emphasizes the activity of inquiry in solving these problems. Develop students' basic cognitive ability and comprehensive ability, cultivate students' innovation ability, problemsolving and other advanced thinking ability and judgment. Interdisciplinary integration creates opportunities for project-based learning, breaks the boundaries between disciplines, and further enhances and develops students' cognitive ability. Project-Based Learning promotes the active learning of students by strengthening the learning of educational skills in a cross-sectional and multidisciplinary way but also integrates values such as cooperation, organization, and time management in a practical way. Through a lot of practice, it is found that PBL teaching method can be applied to science learning or language learning, which has a great role in promoting students' learning. Traditional education focuses on the direct transfer of knowledge, while PBL emphasizes acquiring knowledge in the practical process. In other words, PBL is an innovative teaching method that fully mobilizes students' learning initiative and enthusiasm, likewise enhances their learning motivation.

\section{REFERENCES}

[1] XiaoLi Chen,QingYing Zhang,Pi Guo,JianJun Zhang,CaiXia Liu,Kun Lin,KuSheng Wu.Evaluation of the Effect of PBL and Software Teaching in Medical Statistics Experiments[J]. Continuing Medical Education in China, 2021,13(13):20-24.

[2] ChunXin Huang.Small Micro-projects Study the Value, Objectives and Implementation of Travel Courses $[\mathrm{J}]$.Teaching And Management, 2021(13):33-35.

[3] Jingjing Duan.Practical Exploration To Improve Students' English Thinking Ability Based on Project Learning[J].Primary School Edition of Teaching Monthly (Comprehensive),2021(04):3234.

[4] XinMei Liang.The Teaching Mode Of "Project Learning"in Primary Mathematics is Studied- Take "StatisticsAnd Probability" and "Space and Graphics" Teaching as Examples[J].Education Of TianJin,2021(12):83-85.

[5] XiaoXiao Chen.The Practice and Exploration of Project-based Learning in The Science Teaching of Primary Schools[J].Love science everyday(The frontiers of education),2021(06):15-16.

[6] Li Zhu.Crossover and integration_-Promote Innovation in Information Teaching with the Help of Project-based-learning [J].Enlightenment and wisdom,2021(04):3. 
[7] DeMing Wang.Five Main Elements of the Projectbased-learning [J].Education Today,2021(04):4852.

[8] Birgit Pepin,Rolf Biehler,Ghislaine Gueudet. Mathematics In Engineering Education: a Review of the Recent Literature with a View towards Innovative Practices[J]. International Journal of Research in Undergraduate Mathematics Education,2021(prepublish).

[9] HosseinMohand Hossein,TrujilloTorres JuanManuel,GómezGarcía

Melchor,HosseinMohand Hassan,CamposSoto Antonio. Analysis of the Use and Integration of the Flipped Learning Model, Project-Based Learning, and Gamification Methodologies by Secondary School Mathematics Teachers[J]. Sustainability, 2021,13(5).

[10] Eka Putra Rizki,Iswantir. The Analysis of Implementation of Higher Order Thinking Skills (HOTS) With Problem Based Learning (PBL) $[\mathrm{J}]$. Journal of Physics: Conference Series, 2021,1779(1).

[11] Rex Li. Rediscovering John Dewey[M].Palgrave Macmillan, Singapore:2020-01-01.

[12] D. Coker,J. Marsh,P. Pick,E. Rusjan,W. Thistleton. A Web Centered Project Based Learning Environment[J]. Journal of Educational Technology Systems, 1998,27(2). 